F. med. Genet. (1966). 3, 281.

\title{
Quantitative Variations of Haptoglobins in a Caucasian Family*
}

\author{
G. I. HIGASHI $\dagger$ and H. A. LUBS, Jr.
}

From the Department of Internal Medicine, Yale University School of Medicine, New Haven, Connecticut, and the Veterans Administration Hospital, West Haven, Connecticut, U.S.A.

The inheritance of the common haptoglobin types is well understood. No satisfactory genetic explanation, however, has been advanced to explain quantitative variations in haptoglobin levels, such as those seen in well individuals with either anhaptoglobinaemia or hypohaptoglobinaemia or the various 2-I modified types (Sutton and Karp, I964). Many environmental or host processes are known to influence the haptoglobin level. Haemolysis and hepatocellular failure are known to cause a decrease or absence of haptoglobin (Nyman, 1959). Increased haptoglobin levels have been described in a variety of disorders associated with inflammation or tissue necrosis (Nyman, I959; Jayle and Moretti, 1962; Mathies, Schattenkirchner, and Liebrich, 1963; Robert, Mombelloni, and Crosti, 196I). Administered androgen increases the haptoglobin concentration, and the administration of diethylstilboestrol and ethinyloestradiol to healthy women decreases the haptoglobin level (Borglin and Nyman, 196I). Haptoglobin levels usually reach adult or near adult levels by the age of I year (Bergstrand, Czar, and Tarukoski, I96I). In Nyman's (1959) extensive study, haptoglobin levels were higher in males than in females and varied with the haptoglobin phenotypes. In 144 males the average levels were as follows: type I-I, I44 mg./100 ml.; type 2-I, I $16 \mathrm{mg}$./100 ml., and type 2-2, $88 \mathrm{mg}$./100 ml. In 84 normal women, type $\mathrm{I}-\mathrm{I}$ averaged $115 \mathrm{mg}$./ I00 ml., type 2-I, $95 \mathrm{mg}$./100 ml., and type 2-2, $79 \mathrm{mg} . / 100 \mathrm{ml}$. Thus, in general, the $\mathrm{Hp}^{\mathrm{m}}$ allele results in lower haptoglobin levels and is also generally associated with both anhaptoglobinaemia

Received July 12, 1966.

* Supported in part by USPHS grants No. GM I1078, USPHS No. 2R-37-or, and Special Fellowship No. I F3 CA-I9, 745-OI.

$\dagger$ The study is part of a thesis submitted as partial fulfilment for the Degree of Doctor of Medicine. and various $\mathrm{Hp2}-\mathrm{IM}$ subtypes. The terms 'anhaptoglobinaemia' and ' $\mathrm{Hp} O$ ' signify only the absence of haptoglobin by particular techniques and do not imply complete absence of haptoglobin.

Only a few family studies of haptoglobins using quantitative techniques have been carried out (Gottlieb, Ross, Greenberg, and Wisch, 1963a; Gottlieb, Wisch, and Ross, 1963b; Matsunaga, Murai, and Matsuda, 1962; Murray, Robinson, and Visnich, 1966). Anhaptoglobinaemia has been reported only rarely in Caucasian families (GalatiusJensen, 1958; Harris, Robson, and Siniscalco, 1958; Makela, Eriksson, and Lehtovaara, 1959; Gohler, I964), but a recent report suggests that anhaptoglobinaemia and hypohaptoglobinaemia may not be uncommon in Caucasians (Murray et al., r966). Sutton and Karp (1964) recently suggested that quantitative studies of three-generation pedigrees might be helpful in understanding anhaptoglobinaemia. The present paper is a report of quantitative variation in the haptoglobin levels over four generations in a Caucasian family in which several members had low or absent haptoglobin levels. A Caucasian family of this size in which quantitative levels were studied has not been reported hitherto.

In addition, a modified benzidine staining method, which allows the preservation of the gels and stain with no appreciable change in intensity or clarity of the individual $\mathrm{Hp}-\mathrm{Hb}$ bands for over a year, is described.

\section{Patients}

Certain members of the kindred described had skeletal malformations, and the haptoglobins and various blood groups were investigated for use as 'markers' in linkage studies. Six of the 39 members are deceased, and 25 were studied for Hp typing. Their ages are given in the Figure only if they are under 22 . There was no evidence of significant disease in any family member at the time of study, except for II.2 who had basilar artery disease. 


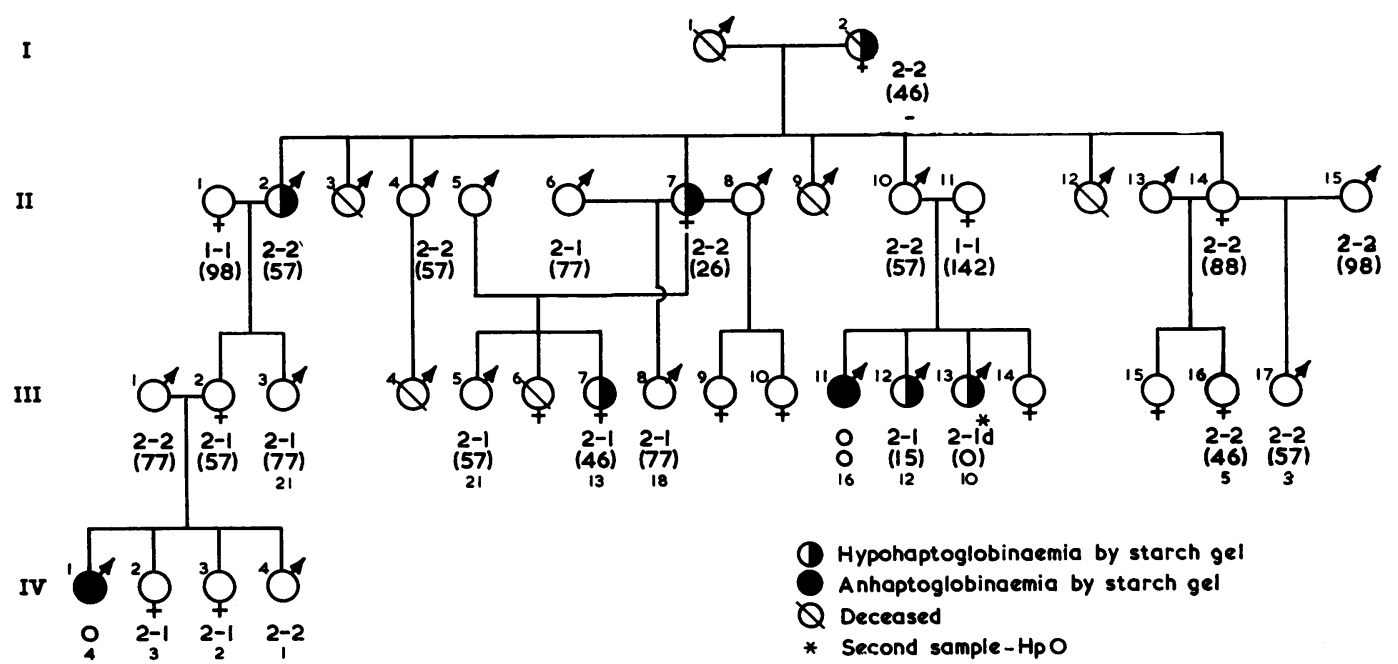

Fig. Pedigree data. The haptoglobin phenotypes are shown directly below the pedigree symbols, e.g., I.2 is $2-2$. III.r3 was anhapto globinaemic on the first sample, but showed a weak Hp 2-Id pattern on the second sample. The quantitative levels in mg./IOO ml. areD shown in parentheses below the phenotype. Lastly, the age of the individual is given if 21 years of age or under. The predominance o 3 low Hp levels in the younger members of the pedigree and thea ssociation of low levels with the $H p^{2}$ alleles is apparent. The qualitative and quantitative techniques correlate well except between the levels of 40 and $60 \mathrm{mg} . / 100 \mathrm{ml}$. Of particular interest is the presence of border $\stackrel{\mathrm{D}}{-}$ line values (under $60 \mathrm{mg} . / 100 \mathrm{ml}$.) in all family members in direct line between the anhaptoglobinaemic individuals. $1 \cdot 2$ died one yeaf $\overrightarrow{0}$ after the studies.

\section{Laboratory Methods}

Blood samples. Sera were separated within two hours after collection and frozen until used. Blood was also collected in tubes containing $\mathrm{I}$ ml. acid-citratedextrose solution for complete blood group studies to confirm inheritance.

Starch gel electrophoresis. All sera were run on vertical starch gel electrophoresis (Smithies, 1959a, b). Hydrolysed starch (S-676, Connaught Medical Research Laboratories, Toronto, Canada) was used in the concentration at which the migration distance of $\beta$ globulin was approximately 2.5 times the migration distance of the slow $\alpha-2$ globulin, namely $13.7 \mathrm{~g}$./100 $\mathrm{ml}$. borate buffer. The gels were run at room temperature $\left(25-30^{\circ} \mathrm{C}\right.$.).

Benzidine stain. The sliced gels were stained in the standard manner with amido black IOB (Smithies, 1959a). The other half of the gel was stained with a modified benzidine procedure originally designed for thin-layer starch gel electrophoresis (Baur, 1963). The modified procedure, in contrast to the usual benzidine stain, allowed the preservation of the stained gel for a much longer period. The stain solution consisted of $0.2 \%$ aqueous benzidine dihydrochloride (Fisher Scientific Co.), $0.2 \%$ acqueous sodium nitroprusside (Fisher Scientific Co.), and I \% glacial acetic acid. Just before use, $0.2 \mathrm{ml}$. $30 \%$ hydrogen peroxide for every roo ml. stain solution was added. The sliced gel was immersed in this mixture for several minutes allowing the $\mathrm{Hb}$ to stain blue. After draining, 3\% aqueous sodium pyrophosphate (reagent grade) was added fo尺 3-5 minutes. The gel was next immersed in absolute methanol for 30 minutes. The original method called for 4 minutes in methanol. Finally, distilled water was added directly to the methanol producing a 10-15 to ratio of water/methanol. This was changed from the method of Baur (1963), in which the gel was washe $\vec{b}$ with distilled water for 15 minutes, and finally immersed in a glycerol/acetic acid/sodium nitrate solution to make the gels white and firm with blue stained $\mathrm{Hp}-\mathrm{Hb}$ bands? The modification described produced a less friable get with greater contrast between the $\mathrm{Hp}-\mathrm{Hb}$ bands and the ivory background. It was excellent for observing qualitative and gross quantitative differences in samples The stained gels were then wrapped in plastic to prevent dehydration and stored in the cold. There was no detectable difference upon inspection of the gels one year $1^{\text {ater. }}$

Quantitative paper electrophoresis. Serures haptoglobin quantitation was performed as describec. by Nyman (1959). Normal adult values have ranged from 26 to $260 \mathrm{mg}$./ $100 \mathrm{ml}$. in various studies (Nyman 1959; Shinton, Richardson, and Williams, 1963; Jayles and Moretti, 1962; Murray et al., 1966), but no definitive criteria for normal levels have emerged.

\section{Results}

Four children had extremely low or absent hapto $\stackrel{\infty}{=}$ globins (Table). III. I I was anhaptoglobinaemic ono two occasions by the usual starch gel technique and by the quantitative determination of the second 
sample. III.I3 showed no haptoglobin staining by either benzidine or amido black staining on the first sample, but the first three of the usual Hp 2-I bands were faintly present on benzidine staining on the second sample four months later. This is comparable to Sutton and Karp's (1964) Hp 2-Id phenotype and will be called 2-Id throughout this communication. Amido black staining was absent in the haptoglobin region but was otherwise normal. No haptoglobin was found by the quantitative technique on the second sample. IV.I was anhaptoglobinaemic on one occasion, but a second sample could not be obtained and there was insufficient serum for quantitation. III.I2 showed a weak Hp2-I pattern on both occasions and a quantitative level of $15 \mathrm{mg}$. $/ 100 \mathrm{ml}$. All of the family members in direct line between the two sibships, where low levels of haptoglobin occurred, had low normal values in the $46-57 \mathrm{mg}$./100 ml. range. In each case when it was measured, however (II.I, II.II, III.I), their spouses were well within the normal range.

TABLE

REPEAT HAPTOGLOBIN FINDINGS IN SEVERELY AFFECTED SUBJECTS

\begin{tabular}{|c|c|c|c|}
\hline \multirow{2}{*}{ Subject } & \multirow{2}{*}{$\begin{array}{c}\text { Sample I } \\
\text { Gel Phenotype }\end{array}$} & \multicolumn{2}{|c|}{ Sample 2 ( 4 months later) } \\
\hline & & Gel Phenotype & $\begin{array}{l}\text { Quantitative } \\
\text { Level }\end{array}$ \\
\hline $\begin{array}{l}\text { III.I I } \\
\text { III.I2 } \\
\text { III.I3 } \\
\text { IV.I }\end{array}$ & $\begin{array}{c}0 \\
\text { Hp 2-I (weak) } \\
0 \\
0\end{array}$ & $\begin{array}{c}0 \\
\text { Hp 2-I (weak) } \\
\text { Hp 2-I (weak) }\end{array}$ & $\begin{array}{c}0 \\
15 \mathrm{mg} \cdot / 100 \mathrm{ml} . \\
0 \\
-\end{array}$ \\
\hline
\end{tabular}

The results of the quantitative and qualitative studies are presented in the Fig. Both techniques revealed low or absent levels when the quantitative levels were less than $40 \mathrm{mg}$./100 ml., and were also in good agreement when the levels were over $60 \mathrm{mg} . / 100 \mathrm{ml}$. Between these levels (46-57 mg./ $100 \mathrm{ml}$.), however, the techniques were in poor agreement. The reasons for these discrepancies are not clear, but presumably they reflect the semiquantitative nature of both techniques and emphasize the need for a better quantitative technique. At present it seems best to employ both techniques, but the technical limitations add significantly to the difficulties in arriving at a satisfactory hypothesis for the haptoglobins.

Because of the presence of atypical or weak $\mathrm{Hp}$ patterns, the three sibs, III.II, III.I2, and III.I3 had complete haemograms done at the drawing of the second sample. Packed cell volume estimates, reticulocyte counts, platelet counts, white blood cell counts, and differentials were normal. Blood group studies were consistent with paternity as shown in Fig. $I$.

\section{Discussion}

Several hypotheses have recently been suggested to explain the genetics of hypohaptoglobinaemia and anhaptoglobinaemia (Gottlieb et al., 1963b; Parker and Bearn, 1963, 1965; Gohler, 1964, Sutton and Karp, 1964). None of these has proved completely satisfactory. The predominance of low levels of haptoglobin in the younger age-groups and quantitative variations have been particularly difficult to explain on a purely genetic basis. The possibility of environmental effects has been discussed by most authors but not considered central to the explanations offered.

The present family raises several additional points which even the broad hypothesis of Parker and Bearn (1963, 1965) does not explain. These include the presence of two sibs with very low levels of $\mathrm{Hp}$ (III.II, III.I2), one of whom has a $\mathrm{Hp} \mathrm{2-I} \mathrm{pattern}$ rather than $\mathrm{Hp} 2-\mathrm{IM}$, and the change from $\mathrm{Hp} O$ to Hp 2-Id in III.r3. In addition, this hypothesis requires each parent of an $\mathrm{Hp}$ o individual to have at least one mutant control gene. The presence of normal $\mathrm{Hp}$ levels not only in a $\mathrm{Hp} \mathrm{I}-\mathrm{I}$ but a $\mathrm{Hp}$ 2-2 parent (II.II and III.I) is against this hypothesis. Conversely, each of the family members in direct line between the $\mathrm{Hp} \circ$ patients shows a low normal value (46-57 mg./100 ml.). These observations suggest that the genetic basis of both low and absent haptoglobin levels is the presence of a single mutant gene. Similar results have been obtained in other large families where quantitative studies have been done (Gottlieb et al., 1963b). It is of particular interest that in each of the hypohaptoglobinaemic families reported by Murray et al. (1966), one of the parents had levels in the same $46-57 \mathrm{mg}$./100 $\mathrm{ml}$. range or lower, though only two were considered low by their criteria (less than $30 \mathrm{mg}$./ $100 \mathrm{ml}$.).

Although Sutton and Karp's hypothesis (1964) is more useful in understanding the present family, certain limitations warrant comment. The genetic evidence presented in their paper forced a pooling of phenotypes $\mathrm{Hp}$ 2-Ia and $\mathrm{Hp}$ 2-Ib as normal, and $\mathrm{Hp} \mathrm{2-IC} \mathrm{and} \mathrm{Hp} \mathrm{2-Id} \mathrm{as} \mathrm{alternative} \mathrm{expressions} \mathrm{of}$ the $H p 2^{c d}$ gene. Whether these genotypes will remain discrete is not clear. Either additional genetic evidence or a change from $\mathrm{Hp}$ 2-Icd to Hp 2-Ie in the same subject would necessitate further alteration in the hypothesis. There are few available data to test this possibility, since sequential studies are infrequently reported. Sutton and Karp were forced to conclude that the genetic basis for 
anhaptoglobinaemia was obscure, and offered no genetic reason why some $H p 2^{m} / H p I$ genotypes should be expressed as $\mathrm{Hp}$ o. Again III.I2 is not explained.

Several modifications in emphasis can be made to Sutton and Karp's hypothesis, which extend the hypothesis, and which can be tested. It is postulated that there is an $H p 2^{m}$ allele, or more likely a series of alleles as suggested by Sutton and Karp (1964), which lead to lower levels of $\mathrm{Hp} 2$ product. The rise to adult levels is delayed in the presence of these alleles, there is an increased sensitivity to certain environmental effects or agents which lower $\mathrm{Hp}$ levels, and the maximum $\mathrm{Hp}$ level in the presence of one $H p 2^{m}$ allele is $46-57 \mathrm{mg}$./10oml. A subject with a $H p 2^{c d} / H p I$ genotype might be observed as $\mathrm{Hp} O$ at age $2, \mathrm{Hp} 2-\mathrm{Id}$ at age 8 with a level of $15 \mathrm{mg}$./100 ml., as $\mathrm{Hp} \mathrm{2-I}$ or $\mathrm{Hp} 2-\mathrm{Id}$ at age 40 with a weak gel pattern and a quantitative level of $25-57 \mathrm{mg}$./100 ml. An appropriate environmental stimulus would return him to $\mathrm{Hp} O$ at any time. Sequential testing of subjects with $\mathrm{Hp}$ 2-IM and $\mathrm{Hp}$ o phenotypes could provide confirmation of this hypothesis in a few years. It would not be necessary to observe the full range of possibilities in a single person. The change from $\mathrm{Hp} \circ$ to $\mathrm{Hp} 2-\mathrm{Id}$ in III.I3, as well as similar earlier reports (GalatiusJensen, 1958; Sutton, Neal, Livingstone, Binson, Kunstadter, and Trombley, 1959; Blumberg and Gentile, 196I) provide support for this hypothesis. This hypothesis is essentially that of Sutton and Karp (I964), with emphasis on the wide range of the age and environmental effects. The various types of low or absent haptoglobins in the present family appear best explained by the presence of a single $H p 2^{c d}$ gene, with differences in phenotypic and quantitative levels resulting from age and environmental effects.

In view of the many known host and environmental effects on $\mathrm{Hp}$ levels summarized in the introduction, it seems more productive to observe these families carefully rather than to create new hypotheses at this time.

\section{Summary}

Quantitative levels of haptoglobin were determined over 4 generations in a Caucasian family in which several members had low or absent haptoglobins. A satisfactory genetic explanation of the hypohaptoglobinaemic members of the present and other similar families has not evolved. It appears very likely that a significant portion both of the quantitative and phenotypic variation described $\mathrm{i}$ 蛋 due to interaction of the environment and age with: the various $\mathrm{Hb}_{2} 2^{m}$ alleles. Serial studies in these? families over a period of years will be necessary to resolve these questions.

A modified staining technique is reported which produces well-stained gels for over a year.

\section{REFERENCES}

Baur, E. W. (1963). Thin-layer starch-gel electrophoresis and plastification method. F. Lab. clin. Med., 61, 166.

Bergstrand, C. G., Czar, B., and Tarukoski, P. H. (I96I). Serum haptoglobin in infancy. Scand. F. clin. Lab. Invest., 13, 576.

Blumberg, B. S., and Gentile, Z. (I96I). Haptoglobins and trans? ferrins of two tropical populations. Nature (Lond.), 189, 897. $\omega$

Borglin, N. E., and Nyman, M. (I96I). Effect of estrogens on the haptoglobin level in the blood. Scand. F. clin. Lab. Invest., 13, 107ే Galatius-Jensen, F. (1958). Rare phenotypes in the $\mathrm{Hp}$ systempo Acta genet. (Basel), 8, 248.

Gohler, W. (1964). Die verteilung der haptoglobintypen in def Bezirken Leipzig and Rostock Sonderformen der Hp-Typen. Wiss. Z.Karl-Marx-Univ. Lpz., 13, 256.

Gottlieb, A. J., Ross, J., Greenberg, M., and Wisch, N. (1963a) Hypohaptoglobinaemia in an American Negro family. Nature (Lond.), 197, 1214.

- Wisch, N., and Ross, J. (1963b). Familial hypohaptoglobin emia: a genetically determined trait segregating from glucose-6 phosphate dehydrogenase deficiency. Blood, 21, 129.

Harris, H., Robson, E. B., and Siniscalco, M. (1958). Atypicato segregation of haptoglobin types in man. Nature (Lond.), 1820 1324.

Jayle, M. F., and Moretti, J. (1962). Haptoglobin: biochemicafgenetic and physiopathologic aspects. Progr. Hemat., 3, 342.

Makela, O., Eriksson, A. W., and Lehtovaara, R. (1959). On the inheritance of the haptoglobin serum groups. Acta genet. (Basel) 9, 149.

Mathies, H. von, Schattenkirchner, M., and Liebrich, K. G. (1963) Der Einfluss von hyaluronidase-Applikationen auf den serumDD Haptoglobin-Spiegel des Menschen. Med. exp. (Basel), 8, 95.

Matsunaga, E., Murai, K., and Matsuda, E. (1962). Inheritance of haptoglobin types in 51 Japanese families. Acta genet. (Basel), 129 262.

Murray, R. F., Robinson, J. C., and Visnich, S. (1966). Observations, on the inheritance of hypohaptoglobinemia. ibid., 16, I 13.

Nyman, M. (1959). Serum haptoglobin. Scand. F. clin. Lab. Invest I1, Suppl. 39.

Parker, W. C., and Bearn, A. G. (1963). Control gene mutation as possible explanation of certain haptoglobin phenotypes. Amer. F. hum. Genet., 15, 159.

, and - (1965). Variations in heterozygous expression as the haptoglobin locus. ibid., 17, 370.

Robert, L., Mombelloni, P., and Crosti, P. (I96I). Studies oP serum haptoglobin in experimental connective tissue disorders? Proc. Soc. exp. Biol. (N.Y.), ro7, 499.

Shinton, N. K., Richardson, R. W., and Williams, J. D. F. (I963) The diagnostic value of serum haptoglobin. In Association of Clinical Pathologists: 70th general meeting. F. clin. Path., 16, 39क

Smithies, O. (1959a). Zone electrophoresis in starch gels and its. application to studies of serum proteins. Advanc. Protein Chemis 14,65 .

(1959b). An improved procedure for starch-gel electrophoresis further variations in the serum proteins of normal individuals Biochem. F., 7x, 585 .

Biochem. F., 7x, 585 .
Sutton, H. E., and Karp, G. W., Jr. (1964). Variations in hetero $-{ }^{\omega}$ zygous expression at the haptoglobin locus. Amer. F. hum. Genet

16, 419. . and Trombley, L. E. (1959). The frequencies of haptoglobig types in five populations. Ann. hum. Genet., 23, 175. 